\title{
The Overall Status of International Values Education Research in the Recent Ten Years
}

\author{
Shumei $\mathrm{Wu}^{1,}$, , Xinghua $\mathrm{Zhao}^{2}$ \\ ${ }^{1}$ School of Marxism, China University of Geosciences (Beijing), Beijing, China \\ ${ }^{2}$ School of Marxism, China Jiliang University, Hangzhou, China
}

Email address:

thecallofthesea@163.com (Shumei Wu)

${ }^{*}$ Corresponding author

To cite this article:

Shumei Wu, Xinghua Zhao. The Overall Status of International Values Education Research in the Recent Ten Years. Education Journal. Vol. 8, No. 6, 2019, pp. 266-273. doi: 10.11648/j.edu.20190806.15

Received: August 19, 2019; Accepted: October 10, 2019; Published: October 23, 2019

\begin{abstract}
The revival and development of values education in the world has become a hot topic in the field of education development in the new century. With the increasing demands of the government and people from all walks of life on the values education, the research on values education has begun to increase in the international academic circles. This paper tries to adopt the method of knowledge mapping, select the literature on "values education" in the SSCI database from 2009 to 2018 as the analysis object, and use CiteSpace software to analyze values education. The paper finds that the number of publications on international values education is increasing year by year, forming a core research field focused on pedagogy, psychology and sociology. The mainstream authors on international values education research are Simon Marginson, Pierre Bourdieu, John Dewey, Albert Bandura, etc. In recent ten years, the hot topics on international values education research mainly focus on six themes. Teacher education, physical education, personal values, choosing the caring setting, digital storytelling and professional identity, and teacher education has become the most popular research topic.
\end{abstract}

Keywords: International Values Education, Cite Space, Knowledge Mapping

\section{Introduction}

With the changes of the social structure, cultural structure and lifestyle structure in various countries in the contemporary world, the structure of the values of the society has also undergone profound changes, the conflicts between values have become increasingly frequent, and the deep connections between values and various social problems have become increasingly apparent. Many global issues such as population aging, racism, immigration wave, new terrorism, AIDS, homosexuality and so on all have different relevance to values Many countries are gradually aware of the importance of values and have issued a variety of national policies and strategic measures to implement values education. Academic circles are showing great interest in values and how to deal with differences between values. Therefore, some scholars said, with the increasing demands of the government and people from all walks of life on the values education, the research on values education has begun to increase in the international academic circles. The revival and development of values education in the world has become a hot topic in the field of education development in the new century [1-2]. In terms of values education, academic circles have made some research achievements. It is not only of academic value but also of practical significance to clarify the status of international scholars' research on values education and to sort out its evolution. The existing research on values education refers to three aspects, values education goal, content and method. The research goal of values education research is to grasp and track the development trend of values education, summarize the beneficial experience and competent practice of values education, and provide advice on the decision-making and policy-making of values education based on the strategic demands of the countries [3]; The research content of values education includes the position, function, implementation institutions, operation mechanism, content approaches, method carrier, guarantee mechanism, overall characteristics and development trend of values education [4-8]; The research methods of values education include field 
investigation, literature research, questionnaire survey, interview, case study, comparative study and other research methods of related disciplines. These researches enrich relevant theory and practice of values education, but most of them focus on theme induction and content analysis, so it is not enough to explore the internal discipline network and knowledge structure of the "research object" itself. Taking this into consideration, this paper, starting from scientometrics method and using the literature data of Social Science Citation Index (SSCI) database, tries to use knowledge mapping [9] method to carry out visual analysis on international values education research, and tries to depict the discipline network, core fields and research hot topics in the process of knowledge production, so as to understand and grasp the wholeness, comprehensiveness and tendency on international values education, hoping to contribute to the research and development of values education in China.

\section{The Data Source and Research Method}

\subsection{The Date Source}

This paper uses the Social Sciences Citation Index (SSCI) database created by the American Institute of Scientific Information as the search database. The retrieval was carried out with specific limits, with "values education" as theme words, "articles" as literature type, "English" as retrieval language, "January 2009 to December 2018" as retrieval time, "“education educational research'; 'education scientific disciplines', Sociology', 'Social sciences interdisciplinary', Ethics, 'Psychology', 'Philosophy'” as retrieval research field. A total of 7,398 articles was retrieved finally.

\subsection{The Research Method}

In terms of the generating and drawing of knowledge mapping, this paper mainly uses CiteSpace software to outline the knowledge structure in the field of international values education research. This software is a visual knowledge mapping software developed based on Java language. It is mainly based on the principle of "co-citation analysis theory" and uses an algorithm such as a pathfinder network to conduct the quantitative analysis of literature in a specific research field, and then presents the critical path of knowledge evolution in this field. The concept of "co-citation Analysis" was first put forward by Henry Small, an American intelligence scientist, in 1973. It refers to that "two articles appear together in the reference catalog of the third cited article, and then the two articles form a co-cited relationship. Literature co-citation analysis is the process of excavating the co-citation relationship of Literature through a set of spatial data." [10] It is generally believed that the excavating of the "co-citation relationship" can reveal important knowledge inflection points in the relevant research field, realize the analysis of the potential dynamic mechanism of the evolution of relevant research field and probe into the development frontier of the field [11]. There is no denying that pure quantitative analysis may not precisely and accurately show the internal development of the discipline, because of its high dependence on data, the analysis results may be slightly different from the mainstream cognition in this field. However, the advantages of quantitative analysis are also undeniable; that is, data analysis can be used to visualize the general development trend, network structure and hot research topics in this field.

\section{Scientific Quantitative Analysis of International Values Education Research}

\subsection{Annual Distribution of Articles on International Values Education}

From 2009 to 2018, a total of 7,398 SSCI articles were retrieved based on the theme word of "values education" under the above-limited conditions. Literature data of the past ten years were imported into Citespace software and classified according to the year of literature measurement, the result shown as in Figure 1.

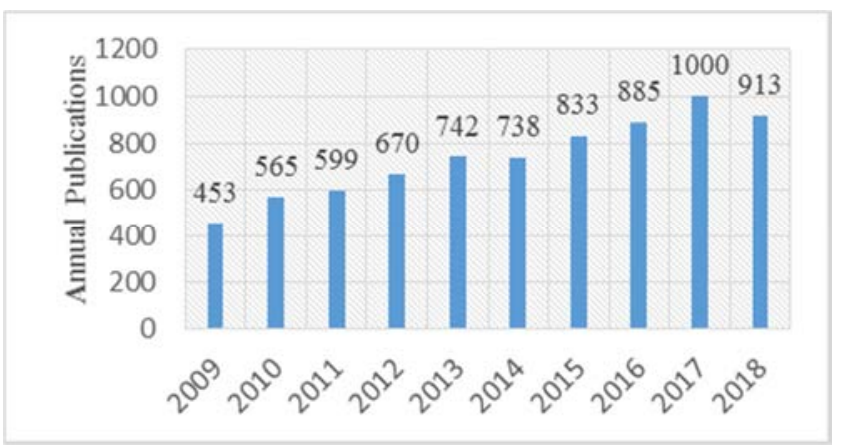

Figure 1. Annual distribution of articles on international values education.

The figure above visually shows that in the past decade, the number of published articles on international values education research has been steadily increasing year by year. The number of published articles has increased from 453 in 2009 to 910 in 2018, with an increased rate of more than $50 \%$. It indicates that the research topic of "values education" has been paid constant attention from the international academic circle, which has become a hot research topic. It is because that influenced by economic globalization. Along with the advancement of economic globalization, the deepening of the exchanges and communication between different countries, the trend of mutual influence, agitation and even competition between different values in the world has become increasingly prominent. The breadth and depth of exchanges, communication, learning and reference between different countries, regions and cultural systems in the field of value philosophy and values education have been developing continuously. Values education has gone beyond the limits of a specific ethnic group or a specific country, showing a cross-regional, cross-cultural and cross-disciplinary development trend, gradually becoming an international and interdisciplinary academic frontier issue. 


\subsection{Distribution of Articles on International Values Education by Journals}

The 7,398 articles retrieved in this paper have been published in various journals, which reflects that the research on the topic of values education involves a wide range of disciplines and presents distinct interdisciplinary characteristics. As Table 1 shows, the top 15 journals with the highest published articles are respectively: International Journal of Sustainability in Higher Education (292 articles), BMC Medical Education (204 articles), Nurse Education Today (201 articles), Higher Education (104 articles), Computers Education (102 articles), Studies in Higher
Education (97 articles), Environmental Education Research (95 articles), International Journal of Science Education (93 articles), Educational Philosophy and Theory (82 articles), Teachers College Record (82 articles), Teachers College Record (82 articles), Academic Medicine (73 articles); Medical Education (73 articles), Teaching and Teacher Education (73 articles), Eurasia Journal of Mathematics Science and Technology Education (72 articles), Higher Education Research Development (67 articles). These 15 journals have published 1,708 articles, accounting for $23.1 \%$ of the total published articles. In terms of research fields, this literature covers a wide range of fields and relatively concentrates on pedagogy, psychology and other fields.

Table 1. The 15 top journals with the highest publications on international values education.

\begin{tabular}{lll}
\hline No & Journal & articles \\
\hline 1 & International Journal of Sustainability in Higher Education & 292 \\
2 & BMC Medical Education & 204 \\
3 & Nurse Education Today & 201 \\
4 & Higher Education & 104 \\
5 & Computers Education & 102 \\
6 & Studies in Higher Education & 97 \\
7 & Environmental Education Research & 95 \\
8 & International Journal of Science Education & 93 \\
9 & Educational Philosophy and Theory & 82 \\
10 & Teachers College Record & 80 \\
11 & Academic Medicine & 73 \\
12 & Medical Education & 73 \\
13 & Teaching and Teacher Education & 73 \\
14 & Eurasia Journal of Mathematics Science and Technology Education & 72 \\
15 & Higher Education Research Development & 67 \\
\hline
\end{tabular}

\subsection{Distribution of Articles on International Values Education by Authors}

In terms of the number of published articles by authors, authors mainly concentrated in the United States, UK and Australia, among which American scholars published the most. The Table 2 below shows five scholars who published more than 10 articles. The first scholar is Cees Van Der Vleuten Cpm, who is a professor of the Department of Educational Development and Research in the Faculty of Health, Medicine and Life Sciences of Maastricht University in the Netherlands, published 13 articles. Ang Chen, who is at the Department of Computer Sciences of Rice University in America, published 12 articles. Hyunju Lee of the Department of Economics of Ryerson University in Canada published 11 articles; Melanie Walker of the University of the Free State Centre for research on higher education and development in South Africa published 10 papers. Williams Jaquitta of Homerton College (Cambridge) published 10 papers, and Anthony r. Artino Jr at Uniformed Services University and 7 others published 9 papers respectively.

Table 2. The top 15 authors with the highest publications on international values education.

\begin{tabular}{lll}
\hline No & Author & articles \\
\hline 1 & Van Der Vleuten Cpm & 13 \\
2 & Ang Chen & 12 \\
3 & Lee H & 11 \\
4 & Walker M & 10 \\
5 & Williams J & 10 \\
6 & Artino Ar & 9 \\
7 & Gonzalo Jd & 9 \\
8 & Johansson E & 9 \\
9 & Lingard L & 9 \\
10 & Solmon Ma & 9 \\
11 & Van Petegem P & 9 \\
12 & Xu Jz & 9 \\
13 & Bogner Fx & 8 \\
14 & Fernandez M & 8 \\
15 & Aguilar M & 7 \\
\hline
\end{tabular}




\subsection{Mainstream Journals on International Values Education Research}

The journals with high publications are not necessarily the mainstream journals in this field. Analysis of co-cited journals in Citespace can reveal the distribution of journals concerned by academia. The total citations reflect the quality and influence of journals as well as which journals are the mainstream journals recognized by western intellectuals. We adopt a pathfinder algorithm to trim the knowledge mapping, and use Citespace software to get the map of co-cited journals, as shown in Figure 2 below.

The larger the node is, the chance of the journal cited is more frequent. The Figure 2 intuitively shows that the top 10 journals of co-cited frequency are respectively Journals of
Research in Science Teaching, Teaching and Teacher Education, Journal of Academic Medicine, Journal of Medical Education, American Educational Research Journal, Higher Education, Journal of Educational Psychology, Studies in Higher Education, Psychological Bulletin, Journal of Personality and Social Psychology. These highly cited journals have constructed the knowledge framework and main structure of international values education research, and have become the most influential journals of international values education research. It is obvious that there is no complete correspondence between journals with the highest citations and those with the highest publications, and some journals with high publications have not attracted the common attention of the academic vicinity.

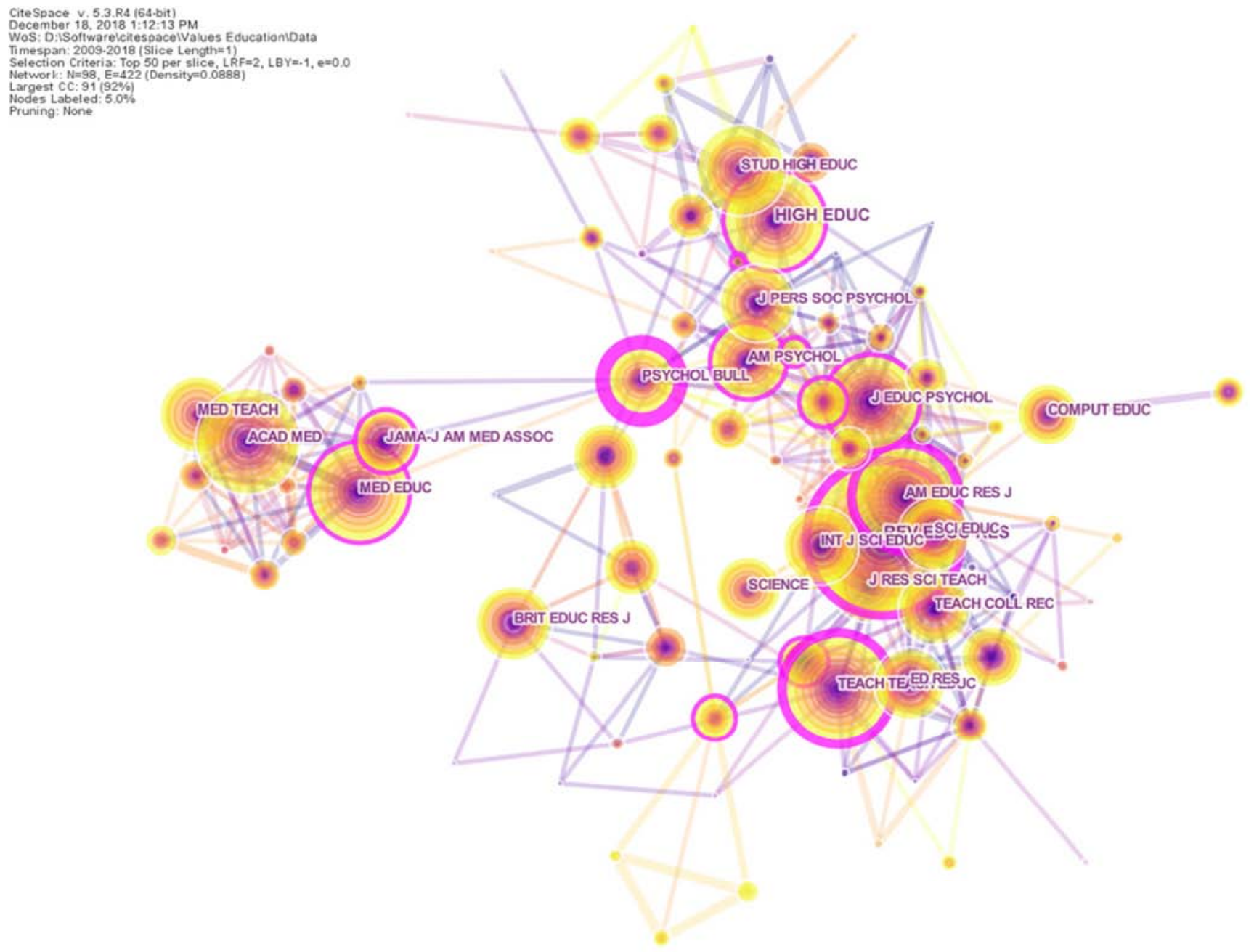

Figure 2. Journals of co-citation map on international values education.

\subsection{Mainstream Institutions on International Values Education Research}

Through Citespace's analysis of "co-citation of publishing institutions, we generated the distribution of co-citation of publishing institutions, showing in Figure 3. According to the figure, the larger node represents the critical position that dominates the whole co-cited network. The top five co-cited institutions respectively are The University of Queensland, Monash University, University of Toronto, The University of Sydney and The Queensland University of Technology, which are all in Australia. The University of Cambridge and the University of London in the UK come in sixth and seventh. Michigan State University and the University of 
Wisconsin in the United States rank eighth and ninth. The University of Hong Kong in China ranks tenth. It can be seen that the most influential publishing institutions of international values education are mainly concentrated in
Australia, followed by the UK. Papers written by Chinese publishing institutions are rarely cited, which reflects that relevant research on international values education of Chinese institutions has not gotten a voice about this.

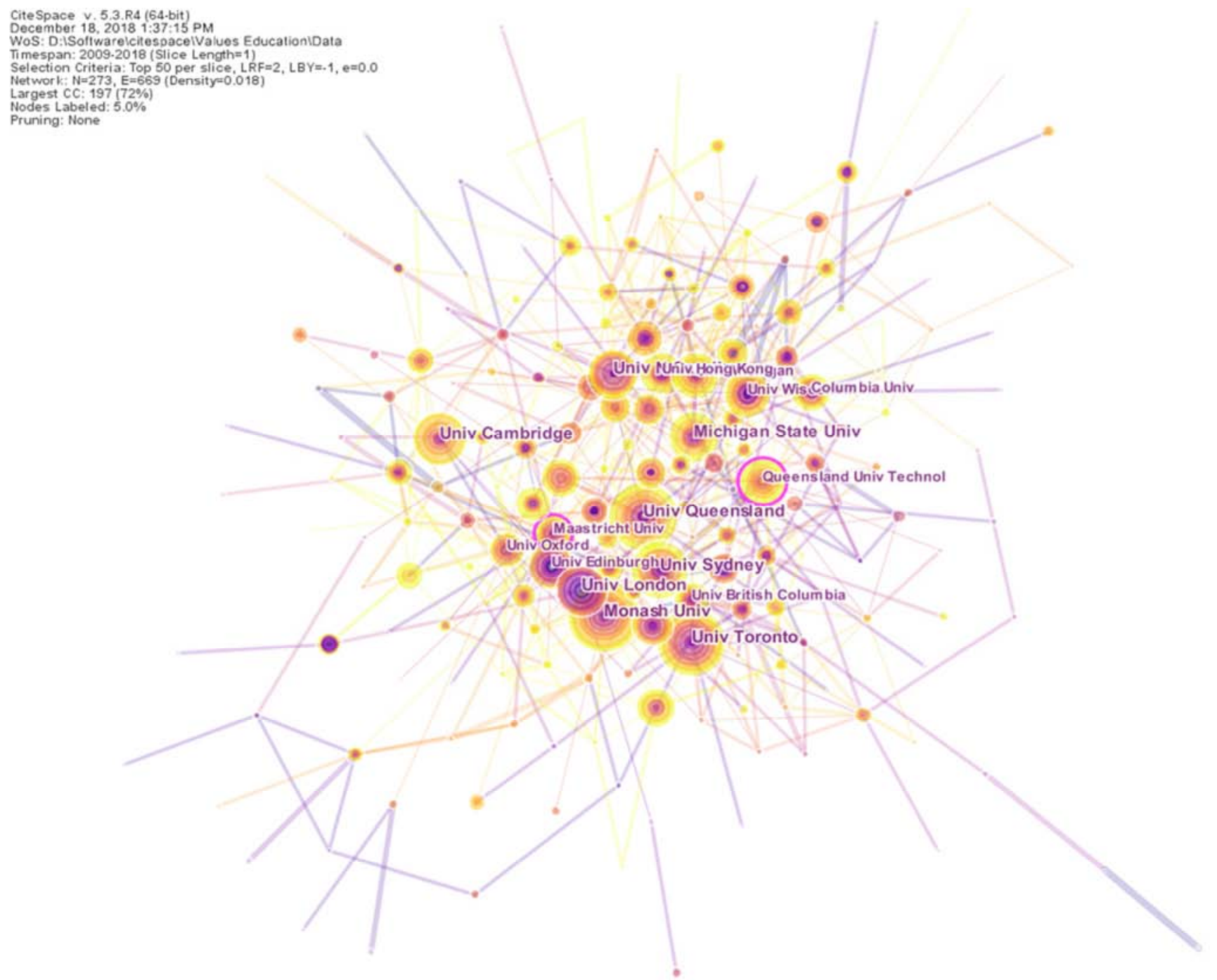

Figure 3. Institutions of co-citation map on international values education.

\subsection{Mainstream Authors on International Values Education Research}

By analyzing "co-cited authors" through Citespace, we generated the distribution of co-cited authors. As shown in Figure 4, the larger the node is, the more influential the author is in the whole co-cited network. The top four most frequently cited scholars are respectively Simon Marginson, Pierre Bourdieu, John Dewey and Albert Bandura.

Simon Marginson [12], a professor of International Higher Education at the University of Oxford, editor-in-Chief of the journal Higher Education, is one of the most cited scholar researchers in the world in the field of higher education studies. He draws on and integrates a range of social science disciplines in his work, primarily political economy and political philosophy, historical sociology and social theory.
He works primarily on globalization and higher education, international and comparative higher education, and higher education and social inequality. Pierre Bourdieu [13] was a french sociologist, anthropologist, philosopher and public intellectual. Bourdieu's significant contributions to the sociology of education, the theory of sociology, and the sociology of aesthetics have achieved vast influence in several related academic fields, such as anthropology, media and cultural studies, education, popular culture, and the arts. John Dewey [14] was an American philosopher, psychologist, and educational reformer whose ideas have been influential in education and social reform. Albert Bandura [15] is a Canadian-American psychologist who is the David Starr Jordan Professor Emeritus of Social Science in psychology at Stanford University. Bandura has been responsible for contributions to the field of education and to several fields of 
psychology, including social cognitive theory, therapy, and personality psychology, and was also of influence in the

transition between behaviorism and cognitive psychology.

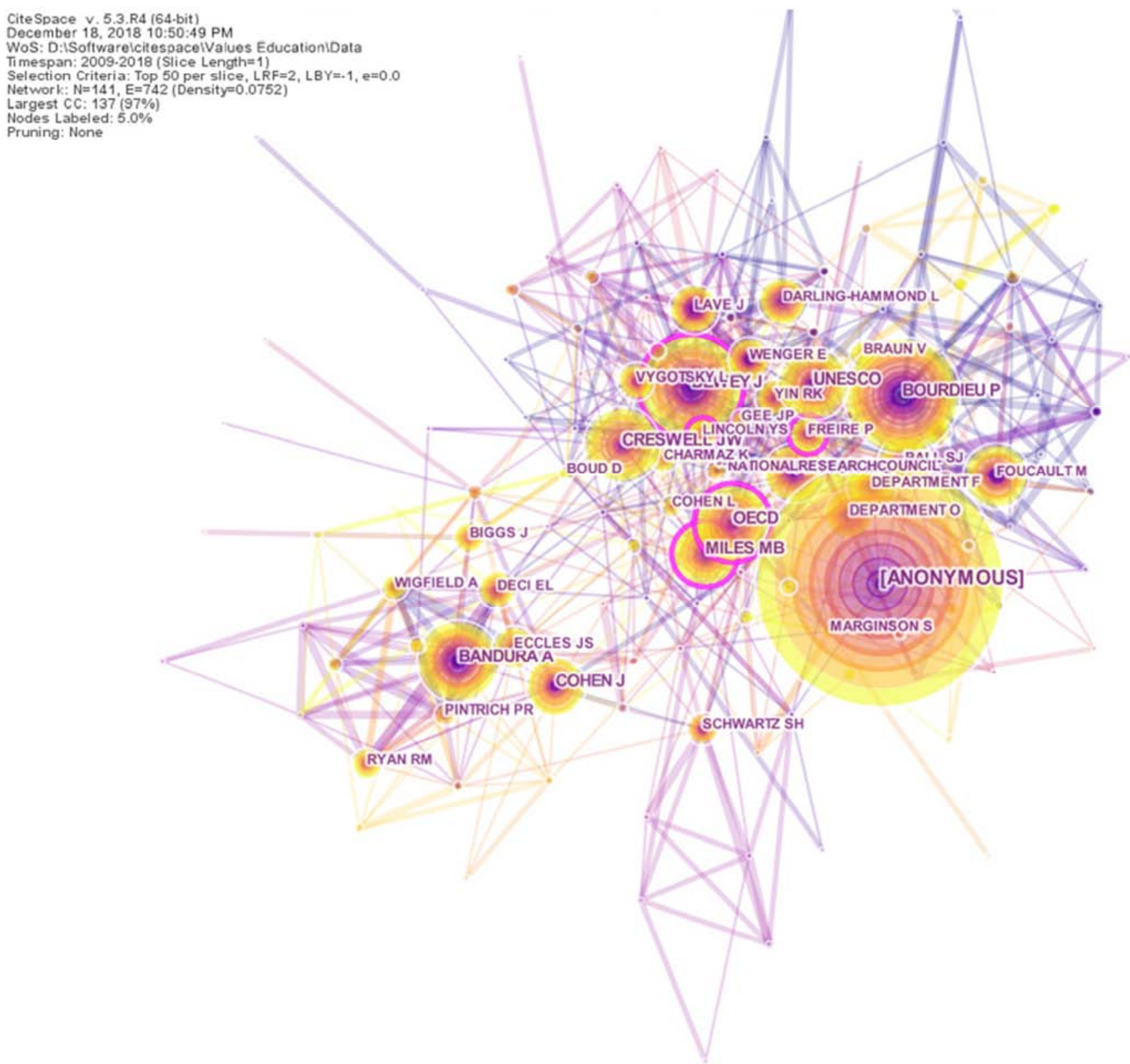

Figure 4. Authors of co-citation map on international values education.

\subsection{The Academic Frontier on International Values Education Research}

To understand the new trend of international values education research, the paper uses Citespace software to cluster the co-cited literature of the past ten years, as shown in Figure 5.

Through cluster analysis, this paper finds that among the relevant research in recent ten years, the most apparent clustering concentrates on six themes: teacher education, physical education, personal value, choosing care setting, digital storytelling and professional identity, which shows that the hot topics of international values education research mainly focus on these issues in recent years. The clustering of teacher education is distinct, this is because teachers play a crucial role in students' values education. Values education deals in a great part with relationships-with the way people treat each other. In the small society of the classroom, students' relationship with the teacher is one of the most important relationships, which has a great potential for positive or negative impact on a young person's values developing and shaping. Teachers have the power to affect the values and character of the young in at least three ways: 1) teachers can serve as effective caregivers-loving and respect their students, helping them succeed and enabling them to experience what values are by having the teacher treat and teach them; 2) Teachers can serve as models - teachers who demonstrate some specific actions 
about values both inside and outside the classroom. Teachers can also model values concern and reasoning by their reactions to morally significant events in the life of the school and the world at large; 3) Teachers can serve as mentors-providing values instructions and guidance through explanation, classroom discussion, storytelling and corrective feedback when students fall into the dilemma of choosing right values [16]. Teacher education has become one of the hot topics in the field of international values education research.
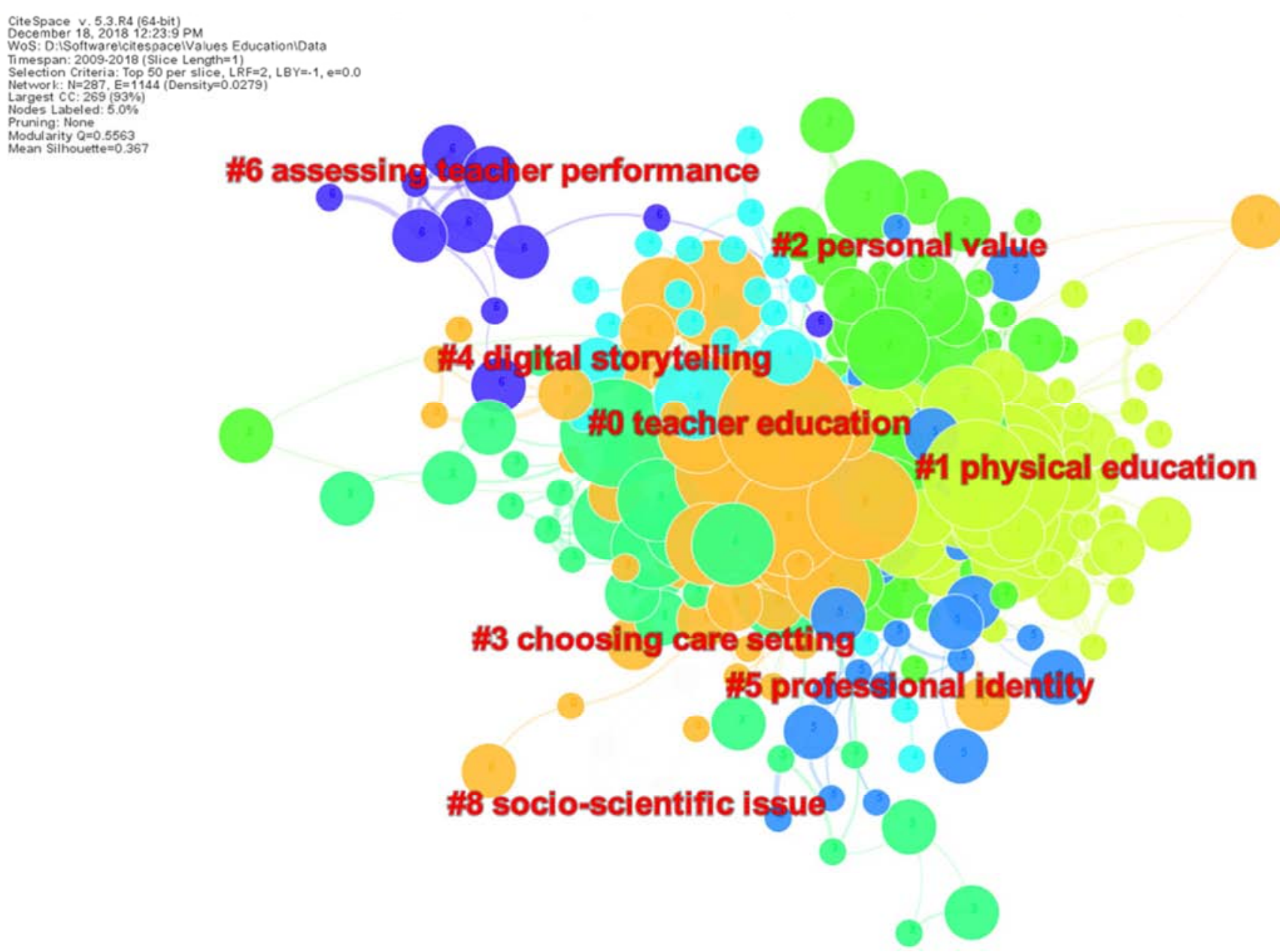

Figure 5. A cluster of co-cited literature on international values education.

\section{Conclusion}

This paper mainly makes a brief quantitative analysis and draws knowledge mapping of the relevant literature on international international values education research with the aid of Citespace literature visualization analysis. Although the accuracy of measurement method limits due to the influence and restrictions of data and algorithm, and it is difficult to understand the internal evolution of text through reading, it could regard as one of the ways that we deepen the understanding. As a method of scientific measurement, Citespace literature visualization software macroscopically outlines the general trend, structure and hot topics of related research on international values education in the past decade, and also draws the "knowledge landscape" about it. This paper finds that the number of published articles on international values education research has increased year by year in the past decade. The research on international values education has a noticeable interdisciplinary feature, which mainly focuses on the fields of pedagogy, philosophy, psychology and sociology, especially pedagogy. The mainstream authors of international values education are Simon Marginson, Pierre Bourdieu, John Dewey, Albert Bandura and others. In recent ten years, the focus of international values education research mainly concentrates on six themes: teacher education, physical education, personal values, choosing the caring setting, digital storytelling and professional identity, among which teacher education is especially important.

\section{Acknowledgements}

This research was supported by 2018 Annual Doctoral Research Cultivation Program of School of Marxism of China University of Geosciences, Beijing (DDMYB 201801). I would also like to give thanks to Xinghua Zhao and Sida Feng who has supported this research. 


\section{References}

[1] Wei Yang, "Contemporary revival and research status of overseas values education", Journal of Teaching and research, 2017 (09). pp. 103.

[2] Xi Wang, Xiuhuai Wang, Jie Gao, The research of western moral education, character education and value education in the 21st century, Journal of Global Education, Vol. 46, No. 7, 2018 (08). pp. 67.

[3] Wei Yang, "Research on values education abroad: objectives, contents and methods", Journal of Ideological and Theoretical Education, 2017 (10). pp. 10-16. K. Elissa, "Title of paper if known," unpublished.

[4] T. Lovat, R. Toomey \& N. Clement (eds.), "International research handbook on values education and student wellbeing”, Dordrecht: The Netherlands: Springer, 2010.

[5] Ahmet Katılmış, "Values education as perceived by social studies teachers in objective and practice dimensions", Journal of Education Sciences: Theory \& Practice, 2017 (05).

[6] Rober Thornberg, "The lack of professional knowledge in values education", Journal of Teaching and Teacher Education, $2008(04)$.

[7] Feryal Cubukcu, "Values education through literature in English classes", Journal of Procedia-Social and Behavioral Sciences, 2014 (116).

[8] J. M. Halstead and M. Taylor, "Learning and teaching about values: a review of recent research", Cambridge journal of Education, Vol. 30, No. 2, 2000.

[9] "Knowledge mapping" is a graph that shows the relationship between the development process and structure of scientific knowledge.

[10] Jie Li, Chaomei Chen, Citespace: text excavating and visualization of science and technology, Beijing: Capital University of Economics and Business Press, 2016, pp. 143.

[11] Jie Li, Chaomei Chen, Citespace: text excavating and visualization of science and technology, Beijing: capital university of economics and business press, 2016, pp. 143. J. Clerk Maxwell, A Treatise on Electricity and Magnetism, 3rd ed., vol. 2. Oxford: Clarendon, 1892, pp. 68-73.

[12] https://www.researchcghe.org/about/profile/simon-marginson/, 2019-08-10.

[13] https://www.britannica.com/biography/Pierre-Bourdieu, 2019-08-10.

[14] https://www.biography.com/scholar/john-dewey, 2019-08-12.

[15] https://www.britannica.com/biography/Albert-Bandura, 2019-08-12.

[16] Thomas Lickona, Education for character: how our schools can teach respect and responsibility, New York, N. Y.: Bantam, c1991, pp. 71-72. 